\title{
Tennis Elbow - Efficacy of local Corticosteroid injection in its Management
}

\author{
Dr. M. A. Q. Ansari ${ }^{1}$, Dr. Sachin A. Shah ${ }^{2}$, Dr. S. R. Jidgekar ${ }^{3}$ \\ ${ }^{1}$ Associate Professor, ${ }^{2}$ Professor and Head, ${ }^{3}$ Senior Resident, Department of Orthopaedics, K.B.N. Institute of \\ Medical Sciences, Gulbarga (Karnataka), India
}

\begin{abstract}
Background: Tennis elbow is a common clinical problem familiar to orthopaedic surgeons. Its etiology and management remains controversial, reflected by the fact that more often it runs a chronic course. This study was designed to know the effectiveness of a local corticosteroid injection in its management.

Materials and Methods: sixty-eight patients (median age, 38 to 41 years), presenting with pain on the lateral side of the elbow for a duration of more than six weeks were enrolled for the study. Patients were consecutively allotted to treatment with corticosteroid injections (Group I, $n=34$ ) or oral analgesics and physiotherapy (Group II, $n=34)$. Injection of $1 \mathrm{ml}$ of triamcinolone acetonide $(10 \mathrm{mg})$ mixed with $1 \mathrm{ml}$ of $2 \%$ lidocaine were given at the site of maximum tenderness for patients in group I. Oral Acetaminophen (1000-2000 mg/day), Ibuprofen (800-1200 mg/day), Diclofenac (100-150 mg/day) or Physiotherapy and an exercise program were given to patients in group II. Results were evaluated based on severity of the elbow complaints, tenderness and cozen's test at six weeks follow-up and compared to the baseline clinical features at presentation.

Results: The incidence was more in the third decade $35.3 \%(n=24)$, with female preponderance $64.7 \%(n=44)$ and the dominant arm being more commonly involved 55.9\% $(n=38)$. Excellent results were found in group I in $n=19(55.9 \%)$ whereas poor results were more in group II in $n=20$ (58.8\%). Group I had poor result only in $n=04(11.8 \%)$ of patients who later underwent further surgical intervention.

Conclusion: Local corticosteroid injections are the most effective treatment for tennis elbow at six weeks and cause early resolution of symptoms.
\end{abstract}

Keywords: Tennis elbow, Lateral epicondylitis, Steroid injection, Elbow pain.

\section{Introduction}

Tennis elbow is a common cause of elbow pain in the general population. 50\% of persons who play tennis regularly will develop lateral elbow symptoms at some point during their careers. Its specific etiology is still uncertain. The initial description of this condition goes back more than a century. It was named "lawntennis arm" by Major ${ }^{[1]}$ in 1883 due to its association with the sport. Men and women are affected equally, with symptoms more commonly seen in the dominant arm. The onset of symptoms is attributed to overexertion of the extremity with repetitive wrist extension and alternating forearm pronation-supination. Risk factors include a history of manual labour with heavy tools and significant strain while performing repetitive tasks. ${ }^{[2]}$ There is no consensus on its single effective and consistent management. We report a prospective case series of sixty-eight patients, where we evaluated the efficacy of local corticosteroid injection and compared it with other standard conservative measures.

\section{Materials And Methods}

This is a prospective randomized study of sixty-eight patients presenting with elbow pain of duration ranging from six to sixteen weeks. The most consistent complaint was of elbow pain leading to impairment of daily activity. Most of them had taken some form of local treatment in the form of massage or icing. All patients were counselled about the treatment options, their advantages, disadvantages, natural history of the condition and informed consent was obtained.

\section{Inclusion criteria:}

All patients with pain on the lateral side of the elbow that increased with pressure on the lateral epicondyle and Cozen's test positive were included in the study. Cozen's test was performed by asking the patient to hold the limb with elbow semiflexed and forearm pronated and then dorsiflex the wrist against resistance applied by the examiner. Severe pain at the lateral aspect of elbow is interpreted as positive test. 


\section{Exclusion criteria:}

Patients with duration of pain less than 6 weeks, elbow deformities, musculoskeletal or neurological disorders, history of treatment with corticosteroids or contraindications to corticosteroids were excluded.

\section{Treatment Modality:}

Group I, Corticosteroid group ( $\mathrm{n}=34)$ : Injection of $1 \mathrm{ml}$ of triamcinolone acetonide (10 mg) mixed with $1 \mathrm{ml}$ of $2 \%$ lidocaine were given at the site of maximum tenderness.

Group II, Conservative group $(\mathrm{n}=34)$ : Patients were advised oral analgesic anti-inflammatory drugs like Acetaminophen (1000-2000 mg/day), Ibuprofen (800-1200 mg/day), Diclofenac (100-150 mg/day) or local application of ointment without massage along with rest in a brace. Physiotherapy in the form of pulsed ultrasound, deep friction massage and an exercise program were given.

\section{Follow-up:}

Patients were reassessed at the end of two and six weeks. Results were evaluated at the end of six weeks based on the criteria as in Table 1.

Table 1: Criteria for evaluation of Results

\begin{tabular}{|l|l|l|l|}
\hline Result & Pain & Tenderness & Cozen's test \\
\hline Excellent & Nil & Nil & $-\mathrm{ve}$ \\
\hline Good & Nil & Deep & $-\mathrm{ve}$ \\
\hline Poor & $+\mathrm{ve} /-\mathrm{ve}$ & Superficial & $+\mathrm{ve}$ \\
\hline
\end{tabular}

\section{Results}

A total of 68 patients participated in the study of which $24(35.3 \%)$ were male and $44(64.7 \%)$ were female (Table 2). The condition is found to be more common in the age group of 30-39 years followed closely by 40-49 years, indicating high prevalence in third and fourth decade (Figure 1). Right side was affected in $55.9 \%(n=38)$ of patients and left side in $44.1 \%(n=30)$ of cases (Table 3), may be due to the fact that most of the people are right handed and tend to use their right hand more than their left (Figure 2). Result evaluated at the end of 6 weeks reveal excellent results in $55.9 \%(n=19)$ of group I patients, whereas only $14.7 \%(n=05)$ were excellent in group II (Table 4). 32.3\% ( $\mathrm{n}=11)$ had good results and only $11.8 \%(\mathrm{n}=4)$ had poor results in group I, whereas $58.8 \%(\mathrm{n}=20)$ had poor outcome from group II (Figure 3) and required other methods of treatment after 6 weeks of follow-up. Most of them were treated with local steroid injection after conclusion of the study.

Table 2: Age and Sex distribution of the study population

\begin{tabular}{|l|l|l|l|}
\hline Age(yrs) & Male & Female & Total \\
\hline$<30$ & 01 & 09 & 10 \\
\hline $\mathbf{3 0 - 3 9}$ & 11 & 12 & 24 \\
\hline $\mathbf{4 0 - 4 9}$ & 08 & 14 & 22 \\
\hline$\geq \mathbf{5 0}$ & 04 & 09 & 13 \\
\hline Total & $24(35.3 \%)$ & $44(64.7 \%)$ & $68(100 \%)$ \\
\hline
\end{tabular}

Figure 1: Age and Sex distribution of the study group

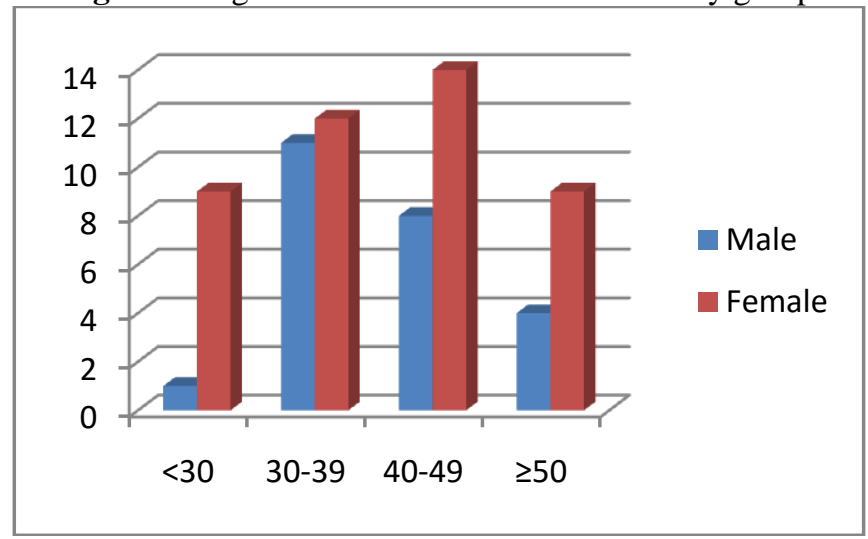


Table 3: Side distribution

\begin{tabular}{|l|l|l|l|}
\hline Side & Male & Female & Total \\
\hline Right & 13 & 25 & 38 \\
\hline Left & 11 & 19 & 30 \\
\hline Total & 24 & 44 & 68 \\
\hline
\end{tabular}

Figure 2: Side distribution

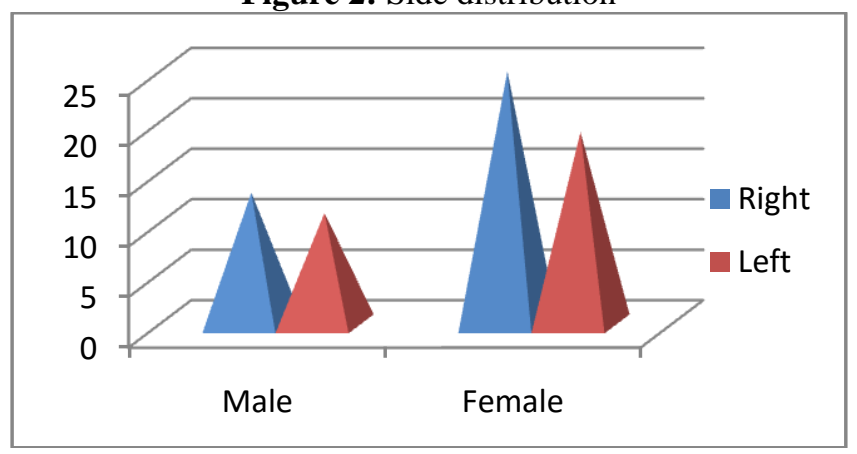

Table 4: Results of both groups compared

\begin{tabular}{|l|l|l|}
\hline Result & Group I No. (\%) & Group II No. (\%) \\
\hline Excellent & $19(55.9)$ & $05(14.7)$ \\
\hline Good & $11(32.3)$ & $09(26.5)$ \\
\hline Poor & $04(11.8)$ & $20(58.8)$ \\
\hline Total & $34(100)$ & $34(100)$ \\
\hline
\end{tabular}

Figure 3: Results of both groups compared

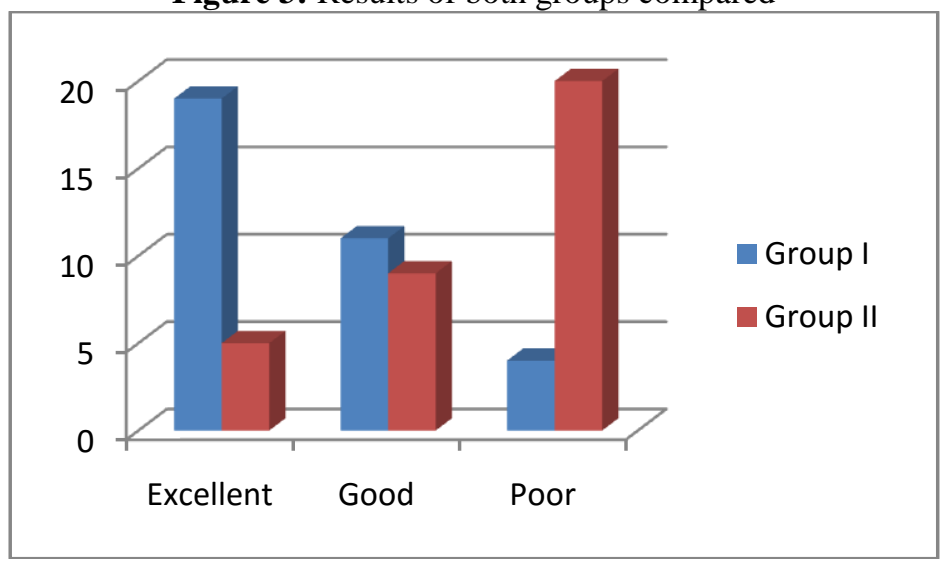

\section{Discussion}

Tennis elbow is a common source of morbidity in tennis players as well as the general population. The term 'Tennis elbow' is a too restricted title since it can occur very commonly in patients who have never played tennis. It occurs in response to the stress of overload and overuse. The repeated pronation-supination motion is apparently more important than the strength used to do the movement. Most patients with lateral epicondylitis will improve over time. Approximately $80 \%$ report symptomatic improvement at one year. ${ }^{[3]}$ Poor prognostic factors include manual labour, dominant arm involvement and long duration of symptoms. ${ }^{[4]}$

The sources of pain generation in tennis elbow are varied. Both intra ${ }^{[8-10]}$ and extra-articular structures may be responsible for symptoms. Refractory tennis elbow can be caused by compression of Posterior interosseous nerve in radial tunnel. ${ }^{[5]}$ Increased activity of extensor carpi radialis brevis muscle, ${ }^{[6]}$ and increased levels of the excitatory neurotransmitter ${ }^{[7]}$ are demonstrated.

Clinical Features include pain over the lateral aspect of the elbow exacerbated by activities involving active wrist extension or passive wrist flexion with the elbow extended (Cozen's test). Maximal tenderness occurs slightly anterior and distal to the lateral epicondyle. It is rarely associated with swelling, erythema or warmth. Magnetic resonance imaging may demonstrate ECRB origin to be separated, thinned, or partially or completely torn. ${ }^{[11]}$ 


\section{Differential Diagnosis:}

- Radial tunnel syndrome

- Osteochondritis dissecans of capitellum

- Radial head arthrosis

- Lateral compartment arthritis

- Posterolateral elbow instability

- Posterolateral elbow plica

- Cervical radiculopathy

- Shoulder periarthritis

\section{Management:}

The most effective mode of therapy and treatment duration remains controversial.

Rest and Nonsteroidal Anti-inflammatory Drugs: Although lateral epicondylitis is characterized as a noninflammatory condition, NSAIDs may relieve pain from associated synovitis or acute inflammation in the surrounding supportive adipose, connective, and muscle tissue. ${ }^{[12]}$ Rest relieves tendon strain and provides time for tendon healing.

Physical Therapy: Stretching of the extensor origin, ultrasound therapy, iontophoresis, electrical stimulation, soft-tissue mobilization, friction massage are other modalities of physical therapy.

Steroid Injection: Many studies have evaluated the efficacy of steroid injection versus NSAIDs and placebo. After a brief period of post injection discomfort, pain relief during early follow-up (5 days to 6 weeks) has been shown to be significantly better in the steroid group than in all others. ${ }^{[13]}$ However, at longer followup (12 weeks to 12 months), results of those who received steroid injection were the same as those of the other treatment groups. Potential explanations for this are that the injections may have weakened the tendon itself or that the patients may have further aggravated the tendon during the relatively painless period early after the injection. ${ }^{[14]}$ Altay et al found no difference in outcomes at one year when lidocaine injection (60 patients) was compared with lidocaine and steroid injection into the extensor origin (60 patients). ${ }^{[15]}$

Local corticosteroid injection is proved to be superior to Cyriax treatment, with a maximum of three injections during a period of one year. ${ }^{[16]}$ Common side effects include skin depigmentation and fat atrophy. Steroids have also been shown to decrease collagen production as well as tenocyte replication. ${ }^{[17]}$ Common extensor tendon rupture is also reported especially with repeated injections. ${ }^{[18]}$

\section{Other Modalities:}

- Botulinum toxin injection. ${ }^{[19]}$

- Autologous blood injection. ${ }^{[20]}$

- Platelet rich plasma (PRP) injection

- Arthroscopy offers several advantages as it allows intra-articular examination for other pathology and permits a shorter postoperative rehabilitation period and an earlier return to work when compared to open procedures..$^{[9]}$

- Surgical debridement is indicated in the $5-10 \%$ of patients when functional disability and pain persist even after 6 to 12 months of nonsurgical management.

\section{Conclusion}

As a whole to conclude from our study, considering factors such as cost and time lost from work, a local Steroid injection for pain relief at acute presentation appears to be the best method to treat tennis elbow rather than an oral or physical approach.

[1]. Major HP: Lawn-tennis elbow. BMJ 1883;2:557.

[2]. Haahr JP, Andersen JH: Physical and psychosocial risk factors for lateral epicondylitis: A population based case-referent study. Occup Environ Med 2003;60:322-329.

[3]. Binder AI, Hazleman BL: Lateral humeral epicondylitis: A study of natural history and the effect of conservative therapy. $\mathrm{Br} \mathrm{J}$ Rheumatol 1983; 22:73-76.

[4]. Haahr JP, Andersen JH: Prognostic factors in lateral epicondylitis: A randomized trial with one-year follow-up in 266 new cases treated with minimal occupational intervention or the usual approach in general practice. Rheumatology (Oxford) 2003;42: 12161225 . 
[5]. Roles NC, Maudsley RH: Radial tunnel syndrome: Resistant tennis elbow as a nerve entrapment. J Bone Joint Surg Br 1972;54:499-508.

[6]. Kelley JD, Lombardo SJ, Pink M, Perry J, Giangarra CE: Electromyographic and cinematographic analysis of elbow function in tennis players with lateral epicondylitis. Am J Sports Med 1994;22:359-363.

[7]. Ljung BO, Alfredson H, Forsgren S: Neurokinin 1-receptors and sensory neuropeptides in tendon insertions at the medial and lateral epicondyles of the humerus: Studies on tennis elbow and medial epicondylalgia. J Orthop Res 2004;22:321-327.

[8]. Nirschl RP, Pettrone FA: Tennis elbow: The surgical treatment of lateral epicondylitis. J Bone Joint Surg Am 1979;61:832-839.

[9]. Baker CL Jr, Murphy KP, Gottlob CA, Curd DT: Arthroscopic classification and treatment of lateral epicondylitis: Two-year clinical results. J Shoulder Elbow Surg 2000;9:475-482.

[10]. Ruch DS, Papadonikolakis A, Campolattaro RM: The posterolateral plica: A cause of refractory lateral elbow pain. J Shoulder Elbow Surg 2006;15: 367-370.

[11]. Mackay D, Rangan A, Hide G, Hughes T, Latimer J: The objective diagnosis of early tennis elbow by magnetic resonance imaging. Occup Med (Lond) 2003;53:309-312.

[12]. $\quad$ Nirschl RP, Ashman ES: Elbow tendinopathy: Tennis elbow. Clin Sports Med 2003;22:813-836.

[13]. Hay EM, Paterson SM, Lewis M, Hosie G, Croft P: Pragmatic randomized controlled trial of local corticosteroid injection and naproxen for treatment of lateral epicondylitis of elbow in primary care. BMJ 1999;319:964-968.

[14]. LewisM, Hay EM, Paterson SM, Croft P: Local steroid injections for tennis elbow: Does the pain get worse before it gets better? Results from a randomized controlled trial. Clin J Pain 2005;21:330-334.

[15]. $\quad$ Altay T, Günal I, Oztürk H: Local injection treatment for lateral epicondylitis. Clin Orthop Relat Res 2002;398:127-130.

[16]. Verhaar AN, Walenkamp GHIM, Van Mameren H, Kester ADM, Van Der Lind AJ. Local corticosteroid injection versus Cyriaxtype physiotherapy for tennis elbow. J Bone Joint Surg (Br) 1996; 78: 128--132.

[17]. Wong MW, Tang YY, Lee SK, Fu BS, Chan BP, Chan CK: Effect of dexamethasone on cultured human tenocytes and its reversibility by platelet derived growth factor. J Bone Joint Surg Am 2003;85:1914-1920.

[18]. Smith AG, Kosygan K, Williams H, Newman RJ: Common extensor tendon rupture following corticosteroid injection for lateral tendinosis of the elbow. Br J Sports Med 1999;33:423-425.

[19]. Wong SM, Hui AC, Tong PY, Poon DW, Yu E,Wong LK:Treatment of lateral epicondylitis with botulinum toxin: A randomized, double-blind, placebo-controlled study. Ann Intern Med 2005;143:793-797.

[20]. Edwards SG, Calandruccio JH: Autologous blood injections for refractory lateral epicondylitis. J Hand Surg [Am] 2003;28:272278. 